\title{
Einfachheit und Komfort für Zahnarzt und Patient
}

LOCATOR, ein Verankerungssystem für herausnehmbare, implantatgestützte Prothesen, bietet Implantatanbietern, Anwendern und Patienten seit anderthalb Jahrzehnten einen erstklassigen Halt. Der kalifornische Hersteller des Originals, ZEST Anchors, sorgt mit seiner 40-jährigen Erfahrung im Bereich innovativer Befestigungstechnologien nun dafür, dass Bewährtes noch besser wird und präsentiert die nächste Generation des Systems: LOCATOR R-Tx. Was der neue Anker in Praxis und Labor leistet wurde auf der 1. offiziellen Pressekonferenz von ZEST Anchors im deutschsprachigen Raum am 16. März in Frankfurt vorgestellt.

Unter der Moderation von Prof. Dr. Andrej Kielbassa, Krems, berichteten Dr. KarlLudwig Ackermann, Filderstadt, Prof. Dr. Ralf Rößler, Heidelberg und ZTM Gerhard Stachulla, Bergen, über erste Erfahrungen mit dem neuen Locater. Die 3 Referenten waren sich einig, dass die neuartige Dura-

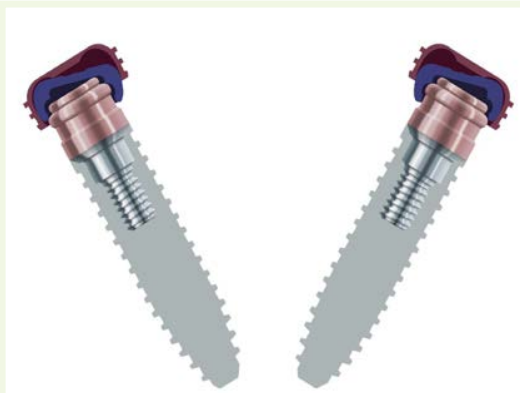

Locator-Attachment-System im Implantat.
Tec-Beschichtung aus Titancarbonitrid nicht nur die Ästhetik optimiert, sondern auch Härte und Abrasionsresistenz steigert. Auch wurde der Schraubmechanismus vereinfacht: Während der bewährte LOCATOR spezielles Werkzeug erfordert, kommt beim LOCATOR R-Tx ein industriestandardisiertes Tool mit .050“/1,25mm Sechskant-Schraubmechanismus zum Einsatz. Weitere Vorteile des neuen Systems: Duale Retentionselemente beim Abutment und bei den Nylon-Retentionseinsätzen harmonisieren mit dem optimierten Matrizengehäuse und sorgen für eine 50 \% höhere Schwenkkapazität (mit bis $\mathrm{zu} 60^{\circ}$ zwischen Implantaten), wodurch der Patient die Prothese leichter ausrichten und punktgenau einsetzen kann. Darüber hinaus weist das neudesignte Matrizengehäuse in ästhetischem, anodisiertem Pink horizontale Rillen und

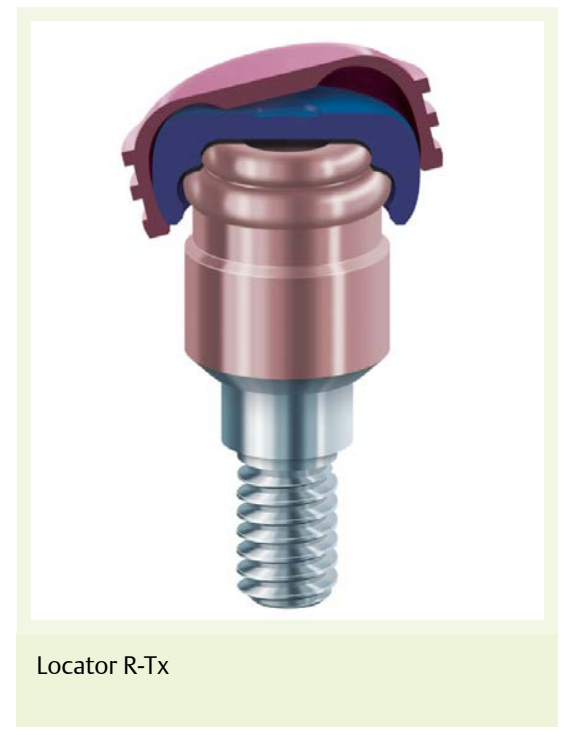

Flächen auf, die für mehr Widerstand gegenüber vertikalen und horizontalen Bewegungen sorgen. Die Referenten bestätigten, dass die unterschiedlichen Versorgungsformen der Implantate durch die Anzahl der Restzähne und durch die finanziellen Möglichkeiten des Patienten bestimmt werden. Auch sind die haptischen Fähigkeiten der älter werdenden Patienten mit in die Planung einzubeziehen.

Eine LOCATOR-Versorgung bringt vor allem Vorteile für ältere, mobilitätseingeschränkte Patienten. Es bestehen auf diese Weise vielfältige Möglichkeiten, sowohl günstige als auch hochwertige Versorgungen anzubieten. Mehr als 90 Hersteller arbeiten mit inzwischen mit ZEST zusammen, um das patentierte LOCATOR-Attachment-System an ihre jeweiligen Implantatsysteme anzupassen. 